\title{
Review Article \\ Promoting Agricultural Research and Development to Strengthen Food Security in South Asia
}

\author{
Ghose Bishwajit \\ Tongji Medical College, Wuhan 430030, China \\ Correspondence should be addressed to Ghose Bishwajit; brammaputram@gmail.com
}

Received 24 January 2014; Revised 12 April 2014; Accepted 14 April 2014; Published 6 May 2014

Academic Editor: David Clay

Copyright (C) 2014 Ghose Bishwajit. This is an open access article distributed under the Creative Commons Attribution License, which permits unrestricted use, distribution, and reproduction in any medium, provided the original work is properly cited.

\begin{abstract}
This study aims to highlight the status of agricultural R\&D in South Asia and contends that creating an effective agricultural research and innovation systems is a vital element to ensure food security in this region. South Asia is home to around one-fourth of mankind and houses the largest proportion of undernourished people in the world. Despite a period of marked economic growth averaging $6 \%$ a year over the past two decades, it remains the world's second poorest region contributing a mere $2.2 \%$ in global annual GDP. Agriculture is the mainstay of South Asian economy employing around $60 \%$ of the total workforce and generating around $20 \%$ of total GDP. South Asia has the recognition of being the second most food-insecure region next only to sub-Saharan Africa. Though there is growing evidence that technological innovation has a key role to play in increasing agricultural production and strengthening food security, agricultural research and development (R\&D) sector has failed to garner sufficient attention till now. This study also depicts the current situation of food security in South Asia and illustrates how agricultural education and innovation hold the master key to solve the food security issues for the world's most densely populated region.
\end{abstract}

\section{Introduction}

The entire economic and agricultural landscape in South Asia has undergone considerable change in the last few decades. All countries in this region have experienced a robust economic growth and improvement in human development indices, reducing poverty and malnutrition to a great extent. Yet, it remains home to nearly half the world's poor and malnourished people [1]. South Asia has estimated 1.7 billion inhabitants, leaving an enormous burden on the relatively small natural and agricultural resource base. It has to feed one-fourth of global population with only $14 \%$ of global arable land [2]. Thomas Malthus (1766-1834) hypothesized that a rapidly growing population would inevitably outstrip any society's capacity to produce enough food which will result in mass starvation and human misery. Though humanity has been largely able to avert the realization of Malthus's prediction thanks to the development of modern cutting-edge technologies, increasing hunger and malnutrition remain a stark reality especially in resource poor countries like in South Asia, where $40 \%$ of world's poor and about half of its malnourished population live [3]. Despite being an agri-based economy, sharing nearly $22 \%$ of the regional GDP, government expenditure on agricultural R\&D remains shockingly low in most countries (Figure 1). This already threatening situation of hunger and food insecurity is farther compounded by poor agricultural infrastructure, inappropriate utilization of resources, and inadequate investment on agricultural R\&D. According to the World Bank, South Asia faces a staggering \$2.5 trillion infrastructure gap to reach its development goals. Though South Asia has now more technical and scientific expertise in R\&D than ever before, current prevalence in hunger and malnutrition indicates that there is still a lot to improve. The fact that by 2050 South Asia is projected to feed around 55\% (5 out of 9 billion) of the global population, which is unquestionably a colossal task, increasing funding on agricultural R\&D remains a top priority in the main development agenda.

\section{Current Scenario of Food Security and Malnutrition in South Asia}

According to Global Food Security Index, 2013, all South Asians countries represent very low food security level. 


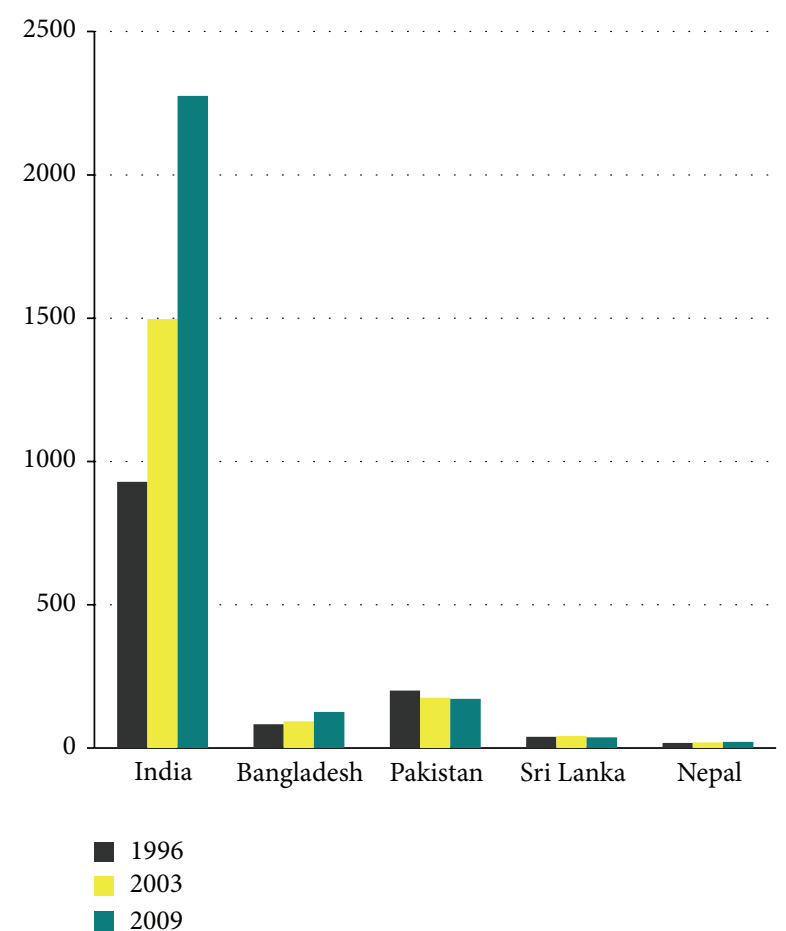

FIgURE 1: Total public agricultural R\&D spending (million \$). Source: the World Bank, http://data.worldbank.org/region/southasia.

Sri Lanka, with a food security score of 48.6 (ranks 60th globally), is by far the most food secured nation in South Asia (compared to 86.8 in USA). India (70), Pakistan (75), and Bangladesh (81) score, respectively, 44.4, 39.7, and 35.3. Nepal has the worst situation scoring 33.8 and rank 84 th out of 107 countries. These figures explain how South Asia is one the most food-insecure region in the world. The number of total food-insecure people remained more or less unchanged since the 1960s but projected to decline in the coming decades (Figure 4).

Despite achieving a remarkable economic growth and considerable increase in agricultural production, household food insecurity and malnutrition continue to be a major concern hindering development efforts in South Asia. Though number of people living below $\$ 1.5$ per day has been decreasing steadily (Figure 5), there are still a huge number of populations who are stuck in extreme poverty. In 2008, around 571 million South Asians lived on less than $\$ 1.25$ per day, the margin of extreme poverty defined by the World Bank. Researchers suggest that national food security and population health are closely intertwined [4]. Increased prevalence of malnutrition is both a determinant and consequence of poverty and food insecurity. Widespread poverty and malnutrition are also the reasons why this region made the least progress towards achieving the Millennium Development Goals (MDGs). South Asia has the highest prevalence of malnutrition in the world [5]. India alone accounts for a quarter of all undernourished people and has the highest number of malnourished children in the world [6].
TABLE 1: Number of full-time equivalent agricultural researchers per million economically active agricultural populations in selected South Asian countries, 1996-2009.

\begin{tabular}{lccc}
\hline & $1996-00$ & $2001-05$ & $2006-09$ \\
\hline India & 56.6 & 50.9 & 43.6 \\
Pakistan & 192.3 & 165.7 & 144.4 \\
Bangladesh & 59.2 & 58.3 & 63.9 \\
Sri Lanka & 143.8 & 139.7 & 156.5 \\
Nepal & 47.7 & 43.9 & 35.4 \\
\hline
\end{tabular}

Source: FAOSTAT 2012, http://www.asti.cgiar.org/.

\section{Current Scenario of Agricultural Research in South Asia}

Globally, driven by rising demand for food, feed, and fuel, food price volatility, climate change, diminishing resources for agricultural production, and increasing cost of the inputs, agriculture research has once again began to gather momentum since the turn of the century. A remarkable shift in the overall research agendas is occurring in many developed and transitional economies with increased attention on food and agricultural sector [7]. During the last decade, global R\&D increased approximately by 22 per cent, from $\$ 26$ billion in 2000 to $\$ 31.7$ billion in 2008. Unfortunately, there is not yet any well-designed agenda for investing in research and technology in South Asian countries. The entire research sector in South Asia still suffers from various political and economic issues such as underinvestment, poor infrastructure, and inadequate flow of qualified researchers (Table 1) and remain greatly dependent on foreign innovation and funds. With a population of around 1.3 billion, India has only 167 government funded agriculture research centres which is the highest in the region, while, for Bangladesh and Nepal, the corresponding figures are 54 and 8, respectively. Between 1996 and 2009, the number of total agricultural researchers decreased by around 6 percent [8]. Constant support by international research partners such as FAO (food and agriculture organization), IFAD (international fund for agricultural development), CGIAR (consultative group on international agricultural research), and IFPRI (international food policy research institute) is helping to minimize the lack of regional research facilities and contributing to the provision of policy advices, research funds, and leveraging agriculture and rural development programs. In India and Pakistan, for example, the research centers heavily rely on CGIAR for supply of genetic materials, training, institutional strengthening, and collaborative research [9].

There is no denying that lack of agricultural research facilities has many wide-ranging effects such as poor implementation of long-term objectives, misallocation, and mismanagement of resources with many economic and environmental externalities. In India and Bangladesh, government subsidies in agriculture are largely dedicated to maintain low fertilizer and pesticide prices and cheaper supply of energy and water. This generally causes overuse and inefficient management of these resources and at the same time creates many adverse effects on environment such as water pollution 
TABLE 2: Agriculture value added (\% of GDP).

\begin{tabular}{lcccccccc}
\hline Year & 2004 & 2005 & 2006 & 2007 & 2008 & 2009 & 2010 & 2011 \\
\hline \% GDP & 19.6 & 19.2 & 18.6 & 18.6 & 18.2 & 18.3 & 18.4 & 18.0 \\
\hline
\end{tabular}

Source: (1) United States Department of Agriculture (USDA) and

(2) FAO 2012.

TABLE 3: Average annual growth rates of agriculture (\%).

\begin{tabular}{|c|c|c|c|c|c|}
\hline & 1971-80 & 1981-90 & 1991-00 & 2001-10 & 1971-2010 \\
\hline High-income countries & 1.83 & 0.97 & 1.25 & 0.47 & 1.14 \\
\hline Transition countries & 0.81 & 1.42 & -4.03 & 2.28 & 0.04 \\
\hline South Asia & 2.19 & 3.70 & 2.76 & 2.80 & 2.86 \\
\hline The world & 2.08 & 2.42 & 2.09 & 2.42 & 2.25 \\
\hline
\end{tabular}

Source: adapted from FAOSTAT 2012, http://faostat.fao.org/.

by pesticide and fertilizer runoff. Power and irrigation water supply system is also very inefficient throughout South Asia which is aggravating the problem of seasonal drought and depleting aquifers [10]. Besides that, indiscrete agricultural policies also compromise the farmer's opportunities to adopt new technologies [11].

In rich countries, where agriculture is a small share of the economy, government may not necessarily increase investment on agricultural $\mathrm{R} \& \mathrm{D}$ as the sector, but, in the subcontinent continent countries, where agriculture has a lion's share of the total economic activity, a meaningful investment in public agricultural research may prove more appreciable impact on the economy. Governments in South Asian countries must realize the fact that the payoff for return on investment on $\mathrm{R} \& \mathrm{D}$ usually takes a long time to appear perceptible and is generally less perceptible when it finally does. Private sector involvement is also crucial to tackle the emerging challenges for agriculture such as environmental pollution, climate change, and speculating the cost of agricultural inputs. Unlike the developed countries, the private sector participation in agricultural research is also low in South Asia countries [12]. As the modern sectors like telecommunication, biopharmaceuticals, and aerospace are developing faster than ever in South Asia, it is also very likely that more and more agricultural research funds be diverted to these sectors and support for public agricultural research will be slowed down. In developed countries, agricultural researches generally emphasize the technologies that suit their own problems and environment, which limits incentives for companies to develop technologies for less-developed countries [13]. Developing countries like in South Asia must therefore focus on capacity-building in research and innovation by their own effort.

\section{Nature of Agricultural Growth and R\&D Spending in South Asia}

An increasing number of countries are experiencing a steady rise in agricultural R\&D spending since 2000. But in South Asia, government expenditure in agriculture has declined or has been very low in recent years in all countries except in India (Figure 1). In Bangladesh, Nepal, Pakistan, and Sri Lanka, agricultural growth has slackened during the same period (Table 2). According to IFPRI, though India's agricultural $\mathrm{R} \& \mathrm{D}$ has been increasing and is currently the highest in South Asia, it is still substantially low compared to its fellow BRIC competitors such as Brazil and China. Though South Asia, as a region, has doubled its agricultural R\&D spending between 1996 and 2009, agricultural R\&D investment to agricultural output ratio remains significantly lower compared to other emerging economies, while the ratio for India is 0.40 per cent, for China 0.50 , and 1.80 for Brazil. Nepal aims to increase it from 0.23 per cent to one per cent. The current rate of increase in investment in agricultural R\&D is clearly insufficient. According to an IFPRI report, this spending must quadruple in the coming years if targets set by these countries are to be met [8]. South Asian population is projected to double by 2050. Ensuring sustainable food supply for this huge population is certainly a daunting task and calls for placing maximum emphasis on agricultural productivity increase. Increased investment on public research has shown to account for 30 percent of the output growth [9]. Table 3 shows that average annual growth rates of agriculture are higher than any other regions in the world. It is also a noticeable fact that the growth rate is not steady and fluctuated substantially since 1970s. Increased growth volatility in agriculture is certainly not a good sign for long-term food security of South Asia's burgeoning population and hence must be addressed by increasing fund and reinforcing research and innovation.

In South Asia, government is the major source of funding for agricultural education. Generally, agricultural education is expensive, and the institutions operate on the basis of an annual budget which depends on the number of students enrolled, previous funding levels, and government capacity to support the institutions [14]. Tuition, fees, and other possible sources of income, such as donations and institutional revenue from farms or the provision of various kinds of services (e.g., veterinary services), are insignificant. As a result, agricultural education and institutions face great difficulties in ensuring properly equipped laboratories and practice farms and fails to emphasize allocating resources on the emerging issues. To meet the growing food demand for 


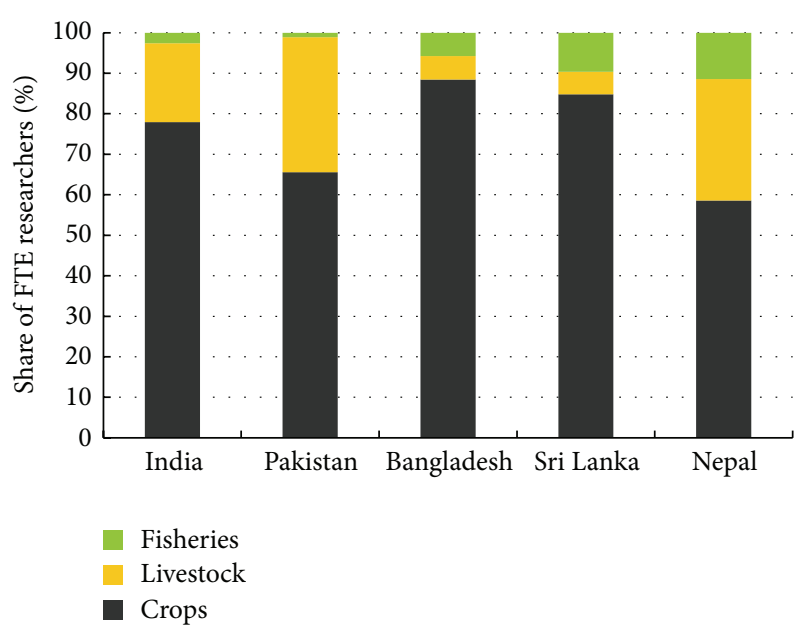

FIgURE 2: Researcher focus by major commodity area, 2009. Source: the state of food insecurity in the world, 2012, FAO report.

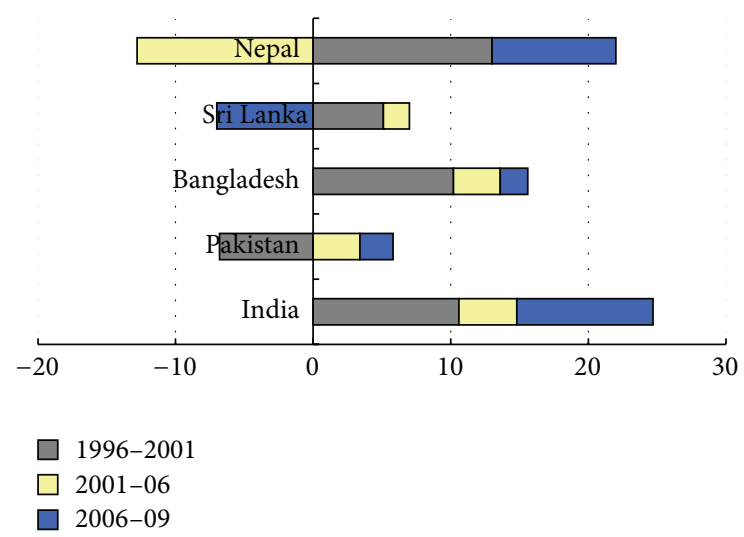

FIGURE 3: Annual growth in public agricultural R\&D spending (\%). Source: the state of food insecurity in the world, 2012, FAO report.

the population burden, farmers are increasingly being forced to adopt monoculture plantations to supply adequate staple grains (rice, wheat, and maize) which comes at the expense of biodiversity loss and severe impacts on people's nutritional status. In Bangladesh, for example, rice production has tripled from 10 million MT in 1971 to over 32 in 2005, but progress for the livestock and fisheries sector has been substantially low [15]. Overdependence on cereal grains with little availability of animals' products largely accounts for widespread malnutrition in South Asia. Though the situation is very pressing from a nutritional point of view, which requires increased attention on the development of the livestock and fisheries sector, unfortunately the proportion of researchers in these sectors remains shockingly low in most South Asian countries (Figure 3). Below are some of the major areas for agricultural research and education in South Asia:

(1) agricultural education that needs to make a more multi- and interdisciplinary approach by incorporating a wide range of related issues including income inequality, gender inequality, farmer's health and welfare, proper utilization of resources, climate change, and relevant demographic parameters;

(2) to reshape agricultural education by abolishing longestablished traditions of academic isolation, increasing collaboration between scientists and policy makers, and emphasizing research and extension through innovative teaching;

(3) to focus not only on temporary increase in agricultural yield but also on developing long-term food security and sustainable agricultural intensification methods with minimal impacts on environment and biodiversity;

(4) governments that need to leverage higher education in agriculture by ensuring continuous support, offering more degrees, scholarships, and research grants, and creating sufficient employment opportunities for agricultural scientists;

(5) building cross-border research partnerships to effectively meet the demand for trained human resources in agriculture, improving communication with national and international academic community, and increasing regional scientific collaboration;

(6) integrating agricultural research with national food and nutritional policy making to ensure better health outcomes and accelerate overall socioeconomic development;

(7) introducing team-teaching, developing case studies to assess problem solving approaches, incorporating practical expertise in community-based researches, and undertaking more practical and field-based exercises.

\section{Role of Investments in Agricultural R\&D to Achieve Food Security and Socioeconomic Development}

Arguably in context of agri-based economies, agricultural sector holds the ultimate promise to slash extreme poverty and combat chronic hunger. Hence, the fight against poverty and hunger must begin with agricultural development. Studies have demonstrated that investments in agricultural research, infrastructure, and education generally rank first or second in terms of return to growth and poverty reduction. Increased $\mathrm{R} \& \mathrm{D}$ investments offer the possibilities to enhance the quantity and quality of agricultural outputs, increased income source, greater food security, and better nutrition. In the long term, investment in $R \& D$ in the agricultural sector will be crucial in all countries, in order to move the technology frontier and sustain productivity growth.

Agriculture holds the key to ensure domestic food security which is in turn inextricably linked to social and national security [16]. Sustainable food supply is fundamental component for maintaining social stability, and chronic food shortage is generally associated with social uprising, increased violence, and political instability. Global food price 


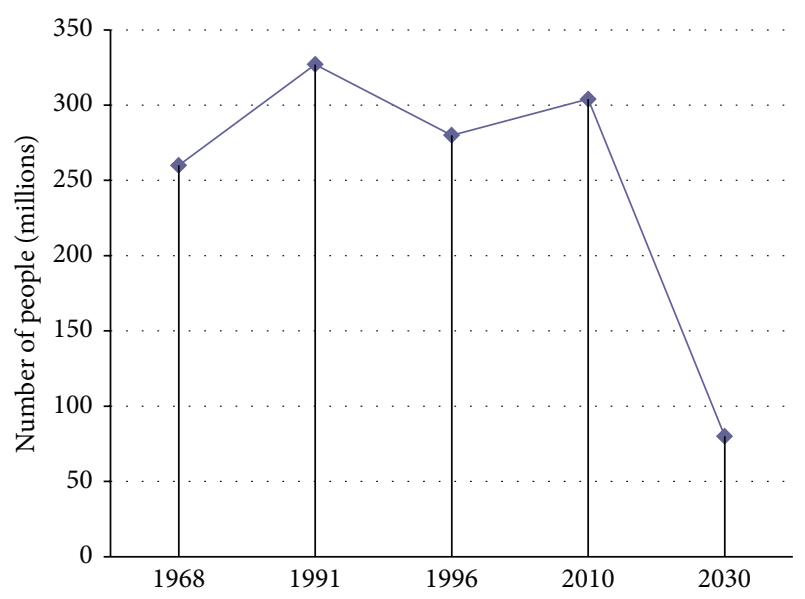

Figure 4: Food-insecure people in South Asia (millions). Source: (1) Global Hunger Index and (2) undernourishment statistics, 2013, http://www.worldometers.info/undernourishment/.

hike during 2007-08 has plunged around 400 million people into poverty and left many countries in the midst of massive civil unrest and economic turmoil [17]. The Green Revolution had an immense influence on reducing poverty and food security in India tripling its food grain production between 1960 and 2000 [18].

Apart from ensuring food security, agriculture has a vital role to play in addressing poverty and rural development issues and accelerating socioeconomic progress [19]. South Asian region is broadly classified as low-income or lowmiddle income category, being the home to nearly half the world's poor and malnourished people. Poverty is predominantly rural phenomenon in South Asia. About $70 \%$ of all South Asians live in rural areas for which agriculture is still the prime source of income. This means that agricultural research along with other development investments holds the key to pave the way out of poverty and offer better food and nutrition security for the subcontinent's huge poor community. According to CGIAR report, increased investment on agricultural $\mathrm{R} \& \mathrm{D}$ is expected to bring a substantial reduction in extreme poverty [20]. Given the increasing phenomenon of widespread poverty (Figure 5) and food insecurity (Figure 4), South Asian countries are faced with extraordinary challenges to develop a sustainable food and agricultural system. Particular attention is required to enhance people's access to income generating activities and food which ultimately depends on the creation of sustainable income source, increasing food supply, and maintaining affordable food price. Since poverty reduction and economic development are ultimately dependent on the overall success of the agriculture sector, a revitalization of the agricultural sector is urgently needed.

\section{Conclusions}

South Asian countries are likely to face severe food crisis by 2050 and the issue of food security is going to be a critical issue in the years to come. Though the growth of

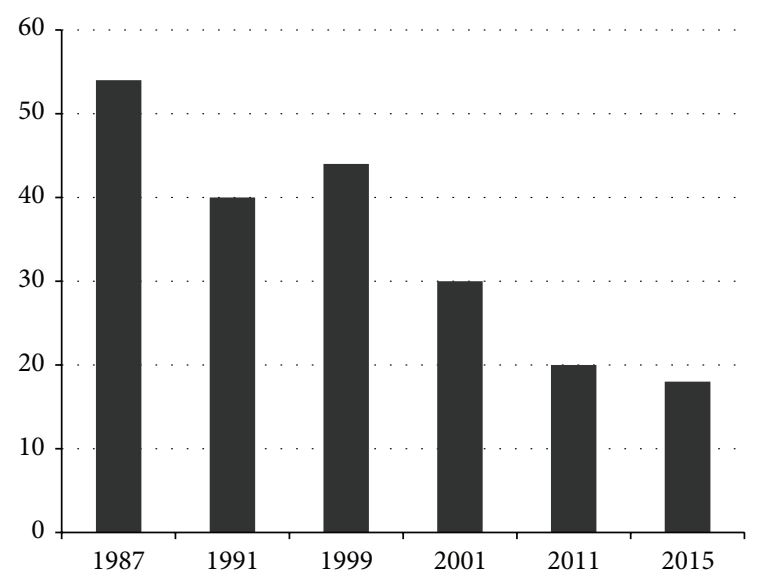

FIgure 5: Percentage of population living under 1.25 \$/day in South Asia. Source: world hunger and poverty facts and statistics, 2013.

nonfarm sectors has gained considerable momentum during the past few decades, agriculture continues to be the lifeblood of the economy. In terms of food insecurity and poverty, South Asia has the distinction of being the worst affected region in the world. Increasing food production in line with demand and ensuring food security for such a huge population is undeniably a daunting task. This is going be hard especially if not accompanied by improvement in other sectors as well as increased R\&D funding, improving research infrastructure, better management of agricultural resources, rural empowerment, and creating more income generation opportunities. This study reveals that South Asia has a lot to improve in all these sectors. This study thus proposes that South Asian countries must focus on increasing investments in agricultural $\mathrm{R} \& \mathrm{D}$ and implement efficient institutional reform in order to contribute more effectively to tackling the emerging challenges in agriculture and food security both at national and regional level (Figure 2). In the coming years, South Asian countries will need to foster long-term productivity policies by investing heavily in agricultural $\mathrm{R} \& \mathrm{D}$, while introducing institutional reforms to create an environment so as to facilitate the adoption of new technologies.

\section{Abbreviations \\ CGIAR: Consultative Group on International Agricultural Research \\ CIMMYT: International Maize and Wheat Improvement Centre \\ MDGs: Millennium Development Goals \\ R\&D: $\quad$ Research and development \\ WDR: World Development Report.}

\section{Conflict of Interests}

The author declares that there is no conflict of interests regarding the publication of this paper. 


\section{References}

[1] G. Bishwajit, S. Sarker, M.-A. Kpoghomou et al., "Self-sufficiency in rice and food security: a South Asian perspective," Agriculture \& Food Security July, vol. 2, article 10, 2013.

[2] United Nations Environment Program, Proceedings of the 2nd Global Conference on Land-Oceans Connection (GLOC-2), Montego Bay, Jamaica, October 2013, http://goo.gl/uHGpKP.

[3] T. Rangaswamy and P. Ramachandran, "Community mental health care in South Asia," World Psychiatry, vol. 12, no. 2, pp. $176-177,2013$.

[4] "FAO's role in investment in agriculture," Food and Agricultural Organization Report, http://www.fao.org/investment-inagriculture/en/.

[5] G. L. Khor, "Update on the prevalence of malnutrition among children in Asia," Nepal Medical College Journal, vol. 5, no. 2, pp. 113-122, 2003.

[6] R. P. Upadhyay and C. Palanivel, "Challenges in achieving food security in India," Iranian Journal of Public Health, vol. 40, no. 4, pp. 31-36, 2011.

[7] P. G. Pardey, J. M. Alston, and R. R. Piggott, Eds., Agricultural ReD in the Developing World: Too Little, Too Late? International Food Policy Research Institute, Washington, DC, USA, 2006.

[8] S. Gert-Jan and R. Michael, "Public agricultural R\&D in South Asia: greater government commitment, yet underinvestment persists," ASTI Synthesis Report, 2012, http://www .asti.cgiar.org/pdf/ASTI-South-Asia-Regional-Synthesis.pdf.

[9] J. Par Gerard Gill, Major Natural Resource Management Concerns in South Asia, Ministry of Agriculture, Lalitpur, Nepal, 1995.

[10] C. Suresh and G. Ashok, Economic Reforms and Food Security: The Impact of Trade and Technology in South Asia, CRC Press, New York, NY, USA, 2005.

[11] D. Sunding and D. Zilberman, "The agricultural innovation process: research and technology adoption in a changing agricultural sector," in Handbook of Agricultural Economics, vol. 1, chapter 4, pp. 207-261, 2001.

[12] K. Fuglie and D. Schimmelpfennig, "Introduction to the special issue on agricultural productivity growth: a closer look at large, developing countries," Journal of Productivity Analysis, vol. 33, no. 3, pp. 169-172, 2010.

[13] K. J. Bradford, J. M. Alston, P. G. Lemaux, and D. A. Sumner, "Challenges and opportunities for horticultural biotechnology," California Agriculture, vol. 58, no. 2, pp. 68-71, 2004.

[14] L. van Crowder, W. I. Lindley, T. H. Bruening, and N. Doro, Agricultural Education for Sustainable Rural Development: Challenges for Developing Countries in the 21st Century, FAO Research, Extension and Training Division, 1999, http://www.fao.org/sd/exdirect/exan0025.htm.

[15] G. Bishwajit, R. Barmon, and S. Ghosh, "Reviewing the status of agricultural production in Bangladesh from a food security perspective," Russian Journal of Agricultural and Socio-Economic Sciences, vol. 1, no. 25, pp. 19-27, 2014.

[16] J. P. Derrickson, A. G. Fisher, J. E. L. Anderson, and A. C. Brown, "An assessment of various household food security measures in Hawaii has implications for national food security research and monitoring," Journal of Nutrition, vol. 131, no. 3, pp. 749-757, 2001.

[17] D. J. Tenenbaum, "Food versus fuel diversion of crops could cause more hunger," Environmental Health Perspectives, vol. 116, no. 6, pp. A254-A257, 2008.
[18] Agriculture for Development, World Development Report, 2008.

[19] P. C. Kesavan and M. S. Swaminathan, "Strategies and models for agricultural sustainability in developing Asian countries," Philosophical Transactions of the Royal Society B: Biological Sciences, vol. 363, no. 1492, pp. 877-891, 2008.

[20] V. B. Joachim, "Agriculture, food and nutrition responding to the crisis," Pontifical Academy of Social Sciences, Acta 16, 2011, http://www.pass.va/content/dam/ scienzesociali/pdf/acta16/acta16-vonbraun.pdf. 


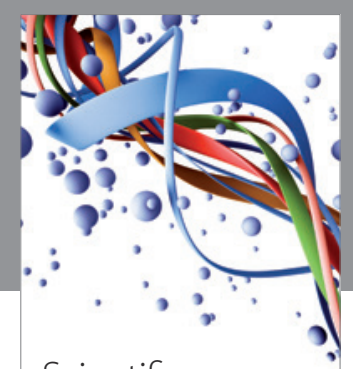

Scientifica
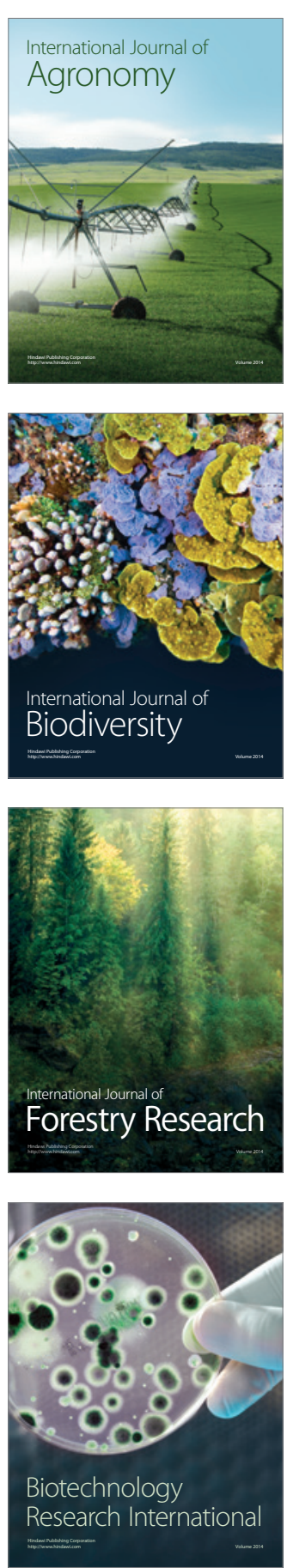
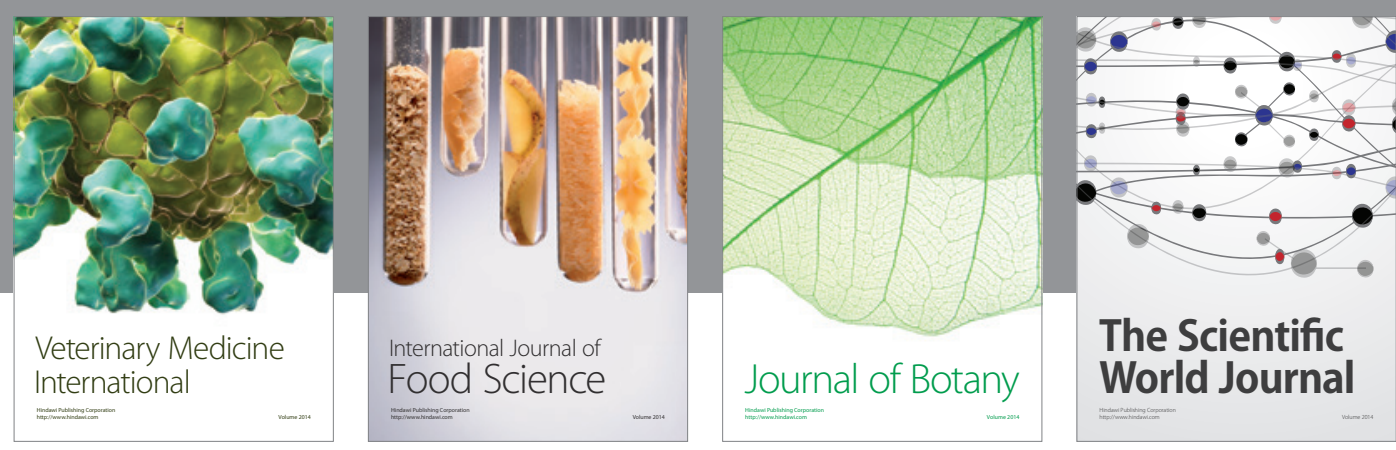

The Scientific World Journal
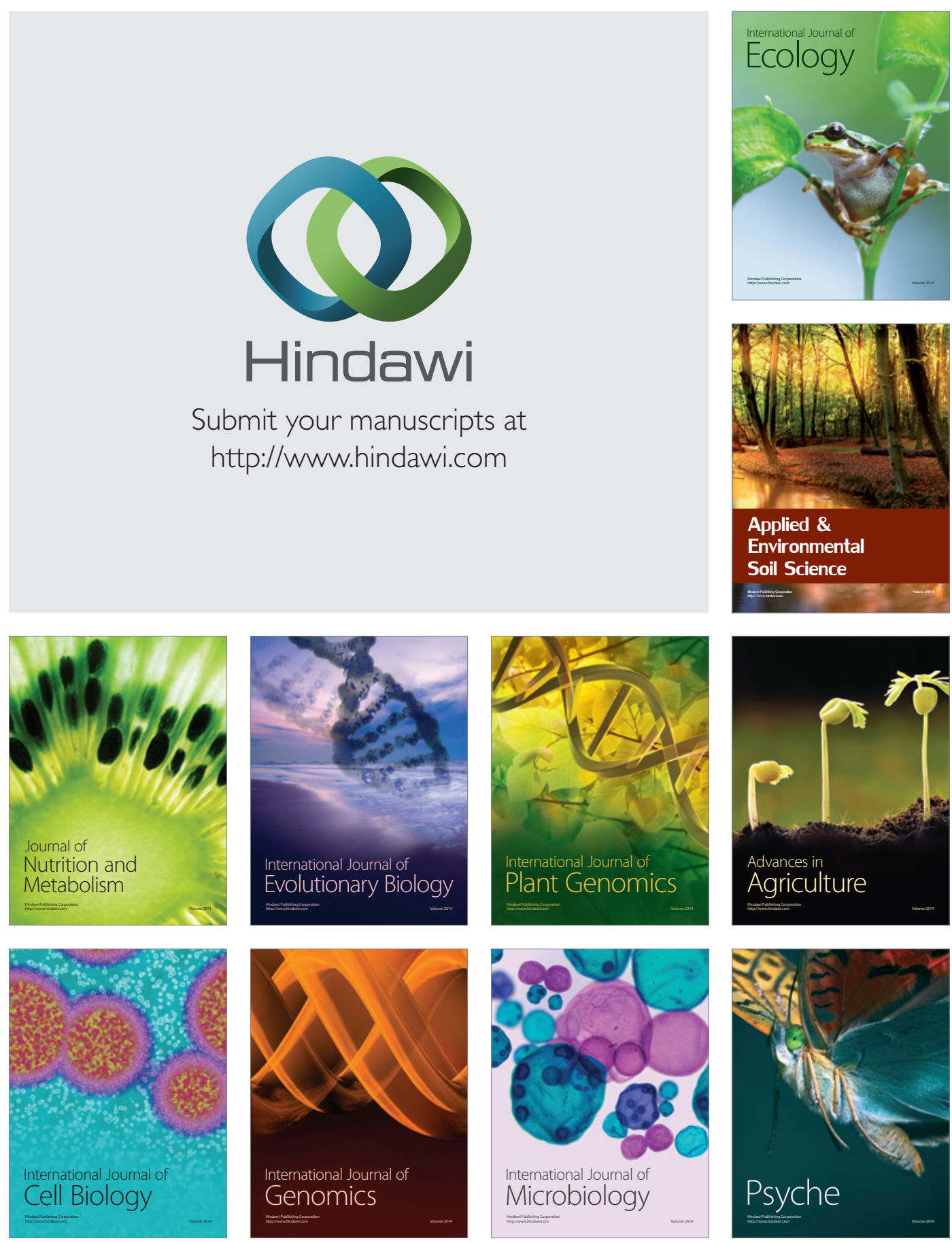